Proceedings

\title{
Influence of peer victimization and self-esteem on child-to-par- ent violence perpetration
}

\author{
Miriam Junco-Guerrero ${ }^{1, *}$, Francisco Javier Fernández-Baena ${ }^{1}$, Milagros Escobar ${ }^{1}$ and David Cantón-Cortés ${ }^{1}$ \\ 1 University of Malaga; M.J.: miriamjunco97@gmail.com; F.J.F.: jfbaena@uma.es; M.E.: mescobar@uma.es; \\ D.C.: david.canton@uma.es \\ * Correspondence: miriamjunco97@gmail.com
}

Publisher's Note: MDPI stays neutral with regard to jurisdictional claims in published maps and institutional affiliations.

\section{(c) (i)}

Copyright: () 2020 by the authors. Submitted for possible open access publication under the terms and conditions of the Creative Commons Attribution (CC BY) license (http://creativecommons.org/licenses/by/4.0/).

\begin{abstract}
The aim of the present study was to analyze the relationship of peer victimization (both as victim and witness) and self-esteem with child-to-parent violence (CPV) towards mother and father, controlling for participants' substances use and age. Alongside, the moderator role of the participants' sex on those relationships was tested. Eight hundred fifty five Spanish high school students (402 female and 453 male) aged between 13 and 20 years $(M=15.29, S D=1.10$ ) were surveyed. Information about CPV was obtained through the Child-to-Parent Aggression Questionnaire (CPAQ). Sociodemographic data, self-esteem and peer victimization were assessed through a selfconstructed questionnaire, the Rosenberg Self-esteem Scale (RSS) and the Violence Exposure Questionnaire (VEQ), respectively. Regarding violence towards mothers, the results of the multiple regression analyses showed a relationship with suffering and witnessing peer victimization, along with lower scores on self-esteem. A moderating role of the aggressor's sex over self-esteem was found, being the relationship of self-esteem with CPV significant only in the case of male participants. With regard to the violence towards fathers, results showed a relationship with witnessing peer victimization, as well as with self-esteem. In this case, a moderating role of the aggressor's sex over self-esteem and being victim of peer violence was found, their relationships with CPV being significant only in the case of male participants. Results confirm the idea that both suffering and witnessing peer violence, as well as low self-esteem levels, have an effect on the probability of CPV perpetration, which differs according to the sex of the perpetrator in the case of self-esteem.
\end{abstract}

Keywords: Child-to-parent violence; Peer violence; Victim; Witness; Self-esteem

\section{Introduction}

Child-to-parent violence (CPV) can be defined as "violence by which children act intentionally and consciously with the desire to cause their parents harm, damage and/or suffering, repeatedly, over time, and with the immediate purpose of obtaining power, control, and domination of their parents to get what they want, through psychological, economic, and/or physical violence" [1].

The data of the prevalence of this phenomenon ranges internationally from 4 to $65 \%$ [2]. However, recent studies have found that, as is occurring with violence against women [3], child-to-parent violence rates are recently increasing due to the confinement situations caused by the current COVID-19 pandemic [4]. As the outbreak spread across the World, nations began to close schools, shut down gatherings, and confine people to their homes. As a consequence of this confinement, a significant percentage of practitioners and parents have reported an increase in violence against parents episodes during lockdown. Because of this, it is important to analyze the consequences of the current COVID-19 pandemic for families suffering CPV. 
Research shows different personal and social characteristics that could be considered as risk factors for the perpetration of violence towards parents [5]. CPV has been associated with variables such as parents' educational style, psychopathology and alcohol/drug use. The present study focuses on the role of peer aggression and self-esteem on the perpetration of child-to-parent violence.

Few studies have analyzed the role of self-esteem among minors who perpetrate $\mathrm{CPV}$, finding that this is one of the personal predictive variables for this type of violence. Aroca, Lorenzo \& Miró [6] found a relationship between low adolescent self-esteem and the aggression towards parents.

Regarding peer violence, this type of hostile behavior towards peers represents a serious problem for coexistence at educational centers, developing environments of conflictive relationships that are not suitable for the child's learning and personal development [7]. Peer violence presents a series of negative consequences at the school, teacher and student levels. Regarding students, several studies show that suffering this type of violence can predict personal maladjustment and psychopathology [8].

It is possible that adolescents who were attacked by their peers use violent behavior against their parents as a method of compensation for feelings of powerlessness, expressing their anger within a safe context such as the family [9]. It is also possible that repeated exposure to violence by peers promotes the accessibility of aggressive thoughts, which, in turn, increases the likelihood of cognitive schemas and aggressive behaviors. Few studies have analyzed the relationship between exposition to peer violence and CPV. Ibabe \& Jaureguizar [10] found that violence among peers was a predictive factor of the adolescents' aggression towards parents. However, studies have not analyzed the differential effects on CPV of being victim or witness of peer violence.

With regard to gender differences in child-to-parent violence, previous research concludes that this is a type of violence exercised by both boys and girls [2]. But there are differences regarding the type of violence exercised, psychological violence being more frequent in the case of girls and physical violence in the case of boys [11]. However, to date no study have tried to clarify the differential role of participants' sex on the relationship of peer violence and self-esteem with CPV. Because of this, the present study aimed to analyze the interactions of participants' sex with exposition to peer aggression (as a victim and as a witness) and participants' self-esteem levels, controlling for substances use by the adolescents.

\section{Method}

\subsection{Participants}

The sample of the present study consisted of 855 participants ( 453 boys and 402 girls), from secondary education schools. Their ages ranged between 13 and 20 years old $(\mathrm{M}=$ $15.29, \mathrm{SD}=1.10)$.

\subsection{Instruments}

In order to collect the socio-demographic data of the participants, a set of questions were asked concerning age, sex, marital status of their parents and the consumption by the participant of any type of alcohol and/or drug.

Child-to-Parent Aggression Questionnaire (CPAQ) [12]. Evaluates CPV through 22 parallel items: 11 referred to the mother and 11 referred to the father. In each block of questions, 7 describe psychological aggressions, 3 physical assaults and 1 financial violence.

Violence Exposure Questionnaire (VEQ) [13]. Evaluates exposure to violence in several contexts (high school, street, home and television). This questionnaire includes 21 items that assesses both direct and indirect violence and its items refer to verbal and physical aggression. 
Rosenberg Self-esteem Scale (RSS) [14]. The scale consists of 10 items (5 positivelyworded and 5 negatively-worded) that assesses global self-esteem.

\subsection{Statistical Analysis}

Statistical analyses of the present study were carried out using the statistical package SPSS (Statistical Package for Social Sciences), version 25. In order to analyze the relationship between child-to-parent aggression, suffering and witnessing peer victimization, and self-esteem multiple linear regression were used.

\section{Results}

Table 1 shows the descriptive data of the subscales of substances use, peer victimization as victim and witness, self-esteem and CPV towards the mother and the father.

Table 1. Descriptive statistics of substances use, peer victimization as victim and witness, self-esteem and CPV against the mother and the father.

\begin{tabular}{lcccc}
\hline Variable & M & SD & Min. & Max. \\
\hline Alcohol & .42 & .84 & 0 & 5 \\
Drugs & .18 & .78 & 0 & 5 \\
Tobacco & .41 & 1.18 & 0 & 5 \\
Peer victimization - victim & 2.34 & 2.35 & 0 & 12 \\
Peer victimization -witness & 6.26 & 2.71 & 0 & 12 \\
Self-esteem & 31.41 & 5.90 & 11 & 40 \\
CPV - mother & 4.56 & 4.02 & 0 & 30 \\
CPV - father & 3.83 & 3.74 & 0 & 27 \\
\hline
\end{tabular}

Next, four independent multiple regression analyses were carried out to determine the variables related to CPV towards mothers and towards fathers, as a function of participant's sex (male and female).

Regarding violence towards mother (table 2), the results of the multiple regression analyses showed a relationship with both suffering and witnessing peer victimization, along with lower scores on self-esteem. A moderating role of the aggressor's sex over selfesteem was found, being the relationship of self-esteem with CPV significant only in the case of male participants.

With regard to control variables, an effect of alcohol use in the case of males and tobacco use in the case of females was found.

Table 2. CPV towards mother as a function of participant's sex.

\begin{tabular}{|c|c|c|c|c|}
\hline Variable & $R^{2}$ & $F \Delta$ & Beta & $t$ \\
\hline Male & .17 & $13.06^{* * *}$ & & \\
\hline Alcohol & & & .21 & $4.08^{* * *}$ \\
\hline Drugs & & & .05 & .96 \\
\hline Tobacco & & & -.02 & -.41 \\
\hline Age & & & -.06 & -1.50 \\
\hline Peer victimization - victim & & & .20 & $3.90^{* * *}$ \\
\hline Peer victimization - witness & & & .15 & $2.98^{* *}$ \\
\hline Self-esteem & & & -.11 & $-2.43^{*}$ \\
\hline Female & .13 & $8.95^{* * *}$ & & \\
\hline Alcohol & & & .08 & 1.40 \\
\hline Drugs & & & -.03 & -.52 \\
\hline Tobacco & & & .21 & $3.77^{* * *}$ \\
\hline Age & & & .04 & .93 \\
\hline Peer victimization - victim & & & .17 & $3.44^{* * *}$ \\
\hline
\end{tabular}




\begin{tabular}{lrr} 
Peer victimization - witness & .11 & $2.20^{*}$ \\
Self-esteem & -.04 & -.89 \\
\hline${ }^{*} p<.05 .{ }^{* *} p<.01 .^{* * *} p<.001$.
\end{tabular}

With regard to the violence towards fathers (table 3), results showed a relationship with witnessing and suffering peer victimization, as well as with self-esteem. In this case, a moderating role of the aggressor's sex over self-esteem and being victim of peer violence was found, their relationships with CPV being significant only in the case of male participants.

Finally, regarding control variables, an effect of alcohol use and age in the case of males, and alcohol and drugs use in the case of females was found.

Table 3. CPV towards father as a function of participant's sex.

\begin{tabular}{|c|c|c|c|c|}
\hline Variable & $R^{2}$ & $F \Delta$ & Beta & $t$ \\
\hline Male & .15 & $11.79^{* * *}$ & & \\
\hline Alcohol & & & .20 & $3.90^{* * *}$ \\
\hline Drugs & & & .06 & 1.16 \\
\hline Tobacco & & & -.02 & -.52 \\
\hline Age & & & -.11 & $-2.48^{*}$ \\
\hline Peer victimization - victim & & & .15 & $2.92^{* *}$ \\
\hline Peer victimization - witness & & & .15 & $3.03^{* *}$ \\
\hline Self-esteem & & & -.15 & $-3.24^{* * *}$ \\
\hline Female & .11 & $7.18^{* * *}$ & & \\
\hline Alcohol & & & .13 & $2.34^{*}$ \\
\hline Drugs & & & .21 & $3.70^{* * *}$ \\
\hline Tobacco & & & -.07 & -1.31 \\
\hline Age & & & .03 & .68 \\
\hline Peer victimization - victim & & & .02 & .43 \\
\hline Peer victimization - witness & & & .15 & $.2 .98^{* *}$ \\
\hline Self-esteem & & & -.04 & -.96 \\
\hline
\end{tabular}

\section{Discussion}

The present study aimed to clarify the role of participants' sex on the relationship of peer violence and self-esteem with $\mathrm{CPV}$.

Regarding peer violence, results agree with those found in studies such as Ibabe and Jaureguizar [10]. Strong relationships of both suffering and witnessing violence with CPV were found in the case of mothers. In the case of CPV towards fathers, a significant relationship was found with witnessing peer victimization, the relationship with being victim of peer violence being a predictor of CPV only in the case of males. As previous research has shown, and consistently with the present data, mothers are significantly more likely to be abused than fathers [15]. Maybe the lower scores on CPV towards father can explain the lack of a significant relationship between peer victimization and CPV towards fathers.

As in Aroca et al. [6] study, a relationship between low self-esteem and child-to-parent violence towards mothers and fathers was also found. However, a moderating role of the aggressor's sex over self-esteem was found in CPV towards both parents, being the relationship of self-esteem with CPV significant only in the case of male participants. This result suggest that male participants may engage in aggressions towards their parents as a mean of regaining a sense of self-worth.

In conclusion, the present study shows the role of participant sex on the relationship of peer victimization and self-esteem with CPV violence. These findings indicate the importance of taking into account those variables in preventing violence towards mothers and fathers. 
Author Contributions: Conceptualization, M.J., F.J.F., M.E., and D.C.; methodology, M.J., A.R., M.E. and D.C.; software, D.C.; formal analysis, D.C.; investigation, M.J. and D.C.; data curation, M.J.; writing - original draft preparation, M.J. and D.C.; writing - review and editing, F.J.F., M.E., and D.C.; supervision, F.J.F. and D.C.; project administration, D.C. All authors have read and agreed to the published version of the manuscript.

Funding: This research received no external funding.

Conflicts of Interest: The authors declare no conflict of interest.

\section{References}

1. Aroca, C. La violencia filio-parental: una aproximación a sus claves [Child-to-parent violence: An approach to its keys]. Doctoral Dissertation. Universidad de Valencia, 2010.

2. Calvete, E.; Orue, I.; González-Cabrera, J. Violencia filio-parental: comparando lo que informan los adolescentes y sus progenitores [Child-to-parent violence: Comparing adolescent-reports with parent-reports]. Rev. Psicol. Clín. Niños adolesc 2017, 4, 9-15.

3. Gulati, G.; Kelly, B. D. Domestic violence against women and the COVID-19 pandemic: What is the role of psychiatry? Int. J. Law Psychiatry 2020, 71, 101594. https://doi.org/10.1016/j.ijlp.2020.101594.

4. Condry, R.; Miles, C.; Brunton-Douglas, T.; Oladapo, A. Experiences of child and adolescent to parent violence in the covid-19 pandemic. University of Oxford, 2020.

5. Ibabe, I. Family predictors of child-to-parent violence: the role of family discipline. An. De Psicol 2015, 31, 615-625. http://dx.doi.org/10.6018/analesps.31.2.174701.

6. Aroca-Montolío, C.; Lorenzo-Moledo, M.; Miró-Pérez, C. La violencia filio-parental: un análisis de sus claves. An. De Psicol 2014, 30, 157-170.

7. Fernández-Baena F. J.; Trianes M. V.; de la Morena M. L.; Escobar M.; Infante L.; Blanca, M. J. Propiedades psicométricas de un cuestionario para la evaluación de la violencia cotidiana entre iguales en el contexto escolar. An. De Psicol, 2011, 27, 102-108.

8. Cangas Díaz, A. J.; Gázquez, J. J.; Pérez-Fuentes, M. C.; Padilla, D.; Miras, F. Evaluación de la violencia escolar y su afectación personal en una muestra de estudiantes europeos. Psicothema 2007, 19, pp. 114-119

9. Cottrell, B.; Monk, P. Adolescent-to-parent abuse: A qualita-tive over-view of common themes. J. Fam. Issues 2004, 25, $1072-1095$. http://dx.doi.org/10.1177/0192513X03261330.

10. Ibabe, I.; Jaureguizar, J. El perfil psicológico de los menores denunciados por violencia filio-parental. Rev. Span Inv Criminológica 2012, 9, 1-19.

11. Ibabe, I.; Jaureguizar, J. ¿Hasta qué punto la violencia filio- parental es bidireccional? [Is child to parent violence bi- directional?] An. de Psicol 2011, 27, 265-277.

12. Calvete, E.; Gámez-Guadix, M.; Orue, I.; González-Diez, Z.; López de Arroyabe, E.; Sampedro, R.; Pereira, R.; Zubizarreta, A.; Borrajo, E. The Adolescent Child-to-Parent Aggression Questionnaire: An examination of aggresion against parents in Spanish adolescents. J. Adolesc 2013, 36, 1077-1081.

13. Orue, I.; Calvete, E. Development and validation of a questionnaire to measure exposure to violence in childhood and adolescence. Rev Int Psicol Ter Psicol 2010, 10, 279-292.

14. Rosenberg, M. Society and the adolescent self-image. Princeton, NJ: Princeton. University Press, 1965.

15. Hong J.S.; Kral M.J.; Espelage D.L.; Allen-Meares P. The social ecology of adolescent-initiated parent abuse: a review of the literature. Child Psychiatry Hum Dev 2012, 43, 431-54. doi: 10.1007/s10578-011-0273-y. 